\title{
The impact of the SSIIa null mutations on grain traits and composition in durum
} wheat

\author{
Ermelinda Botticella ${ }^{1)}$, Francesco Sestili( ${ }^{1)}$, Gianluca Ferrazzano ${ }^{2)}$, Paola Mantovani ${ }^{2)}$, \\ Alessandro Cammerata ${ }^{3)}$, Maria Grazia D'Egidio ${ }^{3)}$ and Domenico Lafiandra*1) \\ 1) Department of Agricultural and Forestry Sciences, University of Tuscia, Via San Camillo De Lellis, 01100 Viterbo, Italy \\ 2) Società Produttori Sementi, Via Macero 1; 40050 Argelato (BO), Italy \\ 3) Research Unit for Cereal Quality, Council for Agricultural Research and Economics, Via Manziana 30, 00189 Roma, Italy
}

\begin{abstract}
Starch represents a major nutrient in the human diet providing essentially a source of energy. More recently the modification of its composition has been associated with new functionalities both at the nutritional and technological level. Targeting the major starch biosynthetic enzymes has been shown to be a valuable strategy to manipulate the amylose-amylopectin ratio in reserve starch. In the present work a breeding strategy aiming to produce a set of SSIIa (starch synthases IIa) null durum wheat is described. We have characterized major traits such as seed weight, total starch, amylose, protein and $\beta$-glucan content in a set of mutant families derived from the introgression of the SSIIa null trait into Svevo, an elite Italian durum wheat cultivar. A large degree of variability was detected and used to select wheat lines with either improved quality traits or agronomic performances. Semolina of a set of two SSIIa null lines showed new rheological behavior and an increased content of all major dietary fiber components, namely arabinoxylans, $\beta$-glucans and resistant starch. Furthermore the investigation of gene expression highlighted important differences in some genes involved in starch and $\beta$-glucans biosynthesis.
\end{abstract}

Key Words: starch, high amylose, durum wheat, dietary fiber.

\section{Introduction}

Durum wheat represents an important crop whose main use is the production of high quality pasta products, and a wide range of different types of bread. The studies of factors determining pasta quality have mainly been addressed to the gluten proteins, whereas the role of the starch fraction has been studied to a lesser extent. Recently, a renewed interest in starch functionality has opened new opportunities for the improvement of wheat based food products: the feasibility to manipulate starch composition, with particular attention paid to the amylose/amylopectin ratio, has resulted in the possibility to develop wheat lines with further improved nutritional and technological characteristics. In particular, high amylose starch has been associated with an increased level of resistant starch (RS) a starch fraction providing several benefits for humans due to its effects similar to dietary fiber (Topping 2007). An increase in resistant starch content

\section{Communicated by T. Anai}

Received February 16, 2016. Accepted May 10, 2016.

First Published Online in J-STAGE on July 21, 2016.

*Corresponding author (e-mail: lafiandr@unitus.it) lowers glycemic index of the food and helps in preventing the onset of serious diet related diseases (Lafiandra et al. 2014, Topping 2007). In addition, a positive effect of high amylose starch on pasta quality characteristics has been reported (Soh et al. 2006).

In wheat the manipulation of the key starch biosynthetic enzymes, such as starch synthases IIa and starch branching enzymes, has permitted the development of durum and bread wheat genotypes with increased amylose content (Hazard et al. 2015, Konik-Rose et al. 2007, Lafiandra et al. 2010, Sestili et al. 2015, Slade et al. 2012, Yamamori et al. 2006). SSIIa enzyme is known to be essential for the elongation of amylopectyn linear chains and its absence result in a drastically changed phenotype in a number of cereal species (Morell et al. 2003). In particular, Yamamori et al. (2006) described the starch phenotype of a complete SSIIanull bread wheat line, obtained crossing single null natural mutants they had previously identified after screening a large bread wheat collection (Yamamori et al. 2000). The work of these authors clearly demonstrated the existence of pleiotropic effects generated by the simultaneous inactivation of the three SSIIa homeoalleles. They found an increase in the apparent amylose content of $27 \%$ compared to the 
control plants what is the actual level of amylose, a changed amylopectin chain branching pattern and the appearance of deformed A-type granules; these characteristics were accompanied by an increased level of RS and novel starch viscosity properties. The introgression of the SSIIa null alleles in the Australian bread wheat variety Sunco confirmed a similar increase in amylose (29\%) along with an important decrease in total starch (15-20\%) (Kosar-Hashemi et al. 2007). Lafiandra et al. (2010) introgressed the SSIIa null alleles in the durum wheat cultivar Svevo detecting a more drastic increase of amylose content of roughly $89 \%$ in respect to the control plant. More recently, Hogg et al. (2013) have produced a new set of partial and complete SSIIa null durum wheat, by the combination of natural and chemical induced mutations. Analysis of these materials has confirmed an increase in amylose content and a drastic decrease in the total amount of starch (by 45\%). Summarizing, wheat grains lacking SSIIa enzymes are reported to have good quality features, due to the higher amylose and resistant starch contents but poor agronomic characteristics, associated with low yield.

In the present work, we have investigated the effects associated with the introgression of SSIIa null mutations in the elite Italian cultivar Svevo, analyzing a large set of mutant families that were characterized for starch characteristics and seed traits. In addition, semolina produced from SSIIa null lines was characterized at rheological level and its composition was investigated.

\section{Materials and Methods}

\section{Plant material}

The two mutant lines Chousen 30 (SSIIa-A null) and Kanto 79 (SSIIa-B null) identified by Yamamori and Endo (1996) had previously been used to produce complete SSIIa null lines in the Italian durum wheat cultivar Svevo. The crossing program included a backcross of the two mutant lines. Starch granule proteins, isolated from half seeds of the two $\mathrm{BC}_{1} \mathrm{~F}_{2}$ populations, were analyzed electrophoretically as described by Sestili et al. (2010). The plants with single SSIIa-A and SSIIa-B null were crossed and double $\mathrm{F}_{2}$ nulls selected electrophoretically. $F_{2}$ plants were backcrossed with Svevo and 144 complete null SSIIa $\mathrm{BC}_{4} \mathrm{~F}_{6}$ mutant families were recovered. Selection of the mutant families was also conducted by molecular markers designed on the mutations of the A and B homeoalleles as described in Shimbata et al. (2005). Fourteen durum wheat mutant lines, showing the best and worst values for grain yield, were selected and characterized in the present study. The set of fourteen lines were grown in field, following a randomized block design, in two different years (2009 and 2010) in Argelato (Bologna-Central Italy). Seed density was 400 seeds $/ \mathrm{m}^{2}$.

Two further lines (H795 and $\mathrm{H} 806$ ), advanced to $\mathrm{BC}_{4} \mathrm{~F}_{9}$, were also grown in the same location in the 2013 an 2014 and seeds harvested were milled to produce semolina.

\section{$R N A$ isolation from immature seed}

Total RNA was extracted from immature seeds, harvested at $21 \mathrm{dpa}$ (days post anthesis), of the durum wheat cultivar Svevo and a derived SSIIa double null line (H770) as reported in Sestili et al. (2010). For reverse transcriptase-mediated PCR studies, cDNA was synthesized from $1 \mu \mathrm{g}$ of total RNA using an oligo(dT) primer and Superscript Reverse Transcriptase III (Life Technologies, Grand Island, NE).

\section{Expression analysis of genes coding the starch biosynthetic enzymes by real time RT-PCR}

qRT-PCR experiments were performed as already described in Sestili et al. (2010). The gene Ta2526 was used as housekeeping gene. The primer pairs for genes GBSSI (Granule Bound starch synthase), SSI, SSII, SSIII (Starch Synthases I, II, III) SBEI, SBEIIa, SBEIIb (starch branchyng enzymes I, IIa IIb), PUL (Pullulanase) and ISAI (Isoamylase I) were used as described by Sestili et al. (2010). The primers for CSLF6 (Cellulose Like Synthase 6) and Ta2526 were reported in Nemeth et al. (2010). Primers specific for SSIV, small and large subunits of ADP-glucose pyrophosphorylase (AGPase) were described in Kang et al. (2013).

Determination of amylose content, total starch, resistant starch, starch damage, $\beta$-glucan and water extractable/ total arabinoxylan content (WE-AX, TOT-AX)

Amylose content was determined by an iodometric assay on starch granules as reported in Sestili et al. (2010). Six technical replicates have been performed for all analyses. A standard curve was obtained using mixtures of potato amylose (Sigma Aldrich) and amylopectin isolated from waxy durum wheat.

Total starch, resistant starch, starch damage and $\beta$-glucan content was determined on whole flour or semolina by using the Megazymes Total Starch, Resistant Starch, Starch Damage and $\beta$-glucan Assay Kits, respectively (Megazyme International Ireland Ltd., Wicklow, Ireland). WE-AX and TOT-AX were determined by a colorimetric method as described in Finnie et al. (2006).

Three technical replicates for each sample were performed. Statistical analysis was performed using one-way ANOVA followed by Tukey t-tests using the R Software.

\section{Protein content}

Wheat grains were milled using Cyclotec 1093 sample mill (Foss Tecator, Höganäs, Sweden) to obtain whole flours. Protein content on the ground samples $(3.5 \mathrm{~g})$ was determined by a Foss NIRSystem 6500 monochromator (Foss NIRSystems INC., Silver Spring, MD) equipped with a sample transport module and a small ring cup, using calibrations developed at the Società Produttori Sementi Spa (Bologna, Italy), based on NIR guidelines for prediction model development (AACC Method 39-00). Reflectance spectra were taken from 400 to $2500 \mathrm{~nm}$ region and recorded as $\log (1 / \mathrm{R})$ at $2 \mathrm{~nm}$ intervals. The WinISI II spectral analytical software (InfraSoft International, Port Matilda, PS) was utilized to 
collect and evaluate quantitatively spectra in the analytical procedures. The values of protein content were calculated directly from the system. Each sample was analyzed twice.

\section{Pasting properties by Rapid Visco Analyzer}

Starch paste viscosity was measured by the Rapid Visco Analyzer (RVA series 4, Newport Scientific, Sydney, Australia) as described in Sestili et al. (2010).

\section{Single Kernel Characterization System}

Grain hardness has been determined by measuring crush force, using the Perten Single Kernel Characterization System (SKCS 4100). The SKCS crushes single kernels between a narrowing crescent-shaped gap and toothed rotor to obtain crush-response profiles and conductivity measurements. From 300 kernel samples, these data are algorithmically integrated to provide kernel hardness, weight, diameter, and percent moisture.

\section{Rheological tests}

Wheat seeds were cleaned, conditioned to a water content of $16 \%$ and left moistened overnight. Semolina samples were obtained by a milling pilot plant (Buhler MLU 202) with three breaking and three sizing passages. Alveographic evaluation was performed on semolina according to the standard method of Chopin alveograph (Chopin, Cedex France) according to standard method UNI 10453. Farinographic tests were carried out by a Brabender apparatus (C.W. Brabender, Duisburg, Germany) according to the standard procedure (ICC 115/1).

\section{Results}

Starch properties: amylose content (AC), resistant starch (RS) and pasting profile

Amylose content was determined for the set of mutant lines and values reported as average of the two years of cultivation (Table 1). Data analysis showed an increase in am- ylose with values ranging from $37 \%$ to $46.2 \%$ compared with the $30.9 \%$ of the control variety Svevo, with large variability among the sister lines. Resistant starch, measured on whole flour, was increased in all the SSIIa null wheat lines with values ranging from $2.4 \%$ to $3.9 \%$ compared with the $0.4 \%$ obtained in Svevo.

All the SSIIa null durum wheat lines showed a flattened pasting profile, as measured by RVA, characterized by drastically lowered values of all the main parameters (peak viscosity, breakdown, setback and final viscosity) compared to Svevo (Fig. 1). As expected, the viscosity values for the single lines varied in the two years, due to the impact of environmental factors (Supplemental Table 1); nonetheless the trend of the pasting profiles among the mutant lines was conserved. Comparison of viscosity curves led to the identification of four lines (H834, H782, H841, and H788) showing the highest values of peak viscosity (PV) and final viscosity (FV) in both the two years and one line (H838) with the lowest values of PV and FV (Fig. 1, Supplemental Table 1).

\section{Thousand grain weight, total starch, $\beta$-glucan and protein} content

The hectoliter weight (HW) and 1,000 grain weight (TGW) were reduced at a variable extent (from $10 \%$ to $20 \%$ ) in the set of the fourteen mutant lines compared to Svevo. The reduction in yield parameters was associated with a reduction in total starch content (TS), estimated between $25 \%-45 \%$ reduction. Comparison of the data set revealed the presence of three lines (H782, H834, H788) presenting the lowest loss in total starch among all the mutant lines and one line, namely H838, resulting the worst for its starch content (Table 1).

The $\beta$-glucan content was significantly higher in all the SSIIa null lines and ranged from $0.28 \%$ to $0.5 \%$ against the $0.13 \%$ of Svevo (Table 1). Notably $\beta$-glucan content was more increased in the line H838, that showed the lowest TS content; whereas it was less increased in the set of three best lines described above. A similar behavior was observed for

Table 1. Evaluation of seed and starch related traits of the fourteen SSIIa null durum wheat lines

\begin{tabular}{|c|c|c|c|c|c|c|c|}
\hline Name & $\begin{array}{c}\text { Amylose content } \\
(\%)\end{array}$ & $\begin{array}{l}\text { Resistant starch } \\
\quad(\mathrm{g} / 100 \mathrm{~g})\end{array}$ & $\begin{array}{c}\text { Total starch } \\
\qquad(\%)\end{array}$ & $\begin{array}{c}\text { HW } \\
(\mathrm{Kg} / \mathrm{hl})\end{array}$ & $\begin{array}{l}1000 \text { grain weight } \\
(\mathrm{g})\end{array}$ & $\begin{array}{l}\text { Protein content } \\
\qquad(\mathrm{g} / 100 \mathrm{~g})\end{array}$ & $\begin{array}{l}\beta \text {-glucan content } \\
(\mathrm{g} / 100 \mathrm{~g})\end{array}$ \\
\hline H742 & $42.4 \pm 3.2^{b c}$ & $2.7 \pm 0.6^{\mathrm{bc}}$ & $39.9 \pm 2.3^{b}$ & $66.3 \pm 3.2^{\mathrm{bd}}$ & $21.6 \pm 1.2^{\mathrm{c}}$ & $16.4 \pm 0.4^{\mathrm{d}}$ & $0.39 \pm 0.21^{\mathrm{b}}$ \\
\hline H748 & $44.5 \pm 1.5^{\mathrm{c}}$ & $2.8 \pm 0.2^{b c}$ & $40.1 \pm 0.9^{b}$ & $62.3 \pm 2.1^{\text {bde }}$ & $20.5 \pm 4.3^{b c}$ & $17.0 \pm 0.5^{\mathrm{bd}}$ & $0.34 \pm 0.12^{\mathrm{c}}$ \\
\hline H758 & $41.2 \pm 2.1^{\mathrm{b}}$ & $3.0 \pm 0.2^{\mathrm{b}}$ & $35.3 \pm 1.3^{c}$ & $61.7 \pm 1.6^{\mathrm{de}}$ & $20.2 \pm 4.6^{\mathrm{bc}}$ & $17.8 \pm 0.4^{b}$ & $0.37 \pm 0.11^{\mathrm{b}}$ \\
\hline H759 & $44.1 \pm 1.4^{\mathrm{c}}$ & $3.9 \pm 0.1^{\mathrm{d}}$ & $37.7 \pm 3.9^{\mathrm{bc}}$ & $59.0 \pm 1.8^{\mathrm{e}}$ & $22.7 \pm 2.3^{\mathrm{bc}}$ & $16.9 \pm 0.8^{\mathrm{bd}}$ & $0.38 \pm 0.21^{\mathrm{b}}$ \\
\hline $\mathrm{H} 770$ & $46.2 \pm 1.3^{c}$ & $3.0 \pm 0.1^{\mathrm{b}}$ & $36.8 \pm 1.9^{b c}$ & $63.0 \pm 2.0^{\mathrm{bd}}$ & $24.1 \pm 1.5^{b}$ & $17.5 \pm 0.4^{\mathrm{d}}$ & $0.33 \pm 0.05^{\mathrm{c}}$ \\
\hline H782 & $40.1 \pm 2.4^{b}$ & $2.8 \pm 0.1^{\mathrm{bc}}$ & $41.1 \pm 1.1^{\mathrm{b}}$ & $66.1 \pm 2.5^{\mathrm{bd}}$ & $23.3 \pm 1.8^{\mathrm{bc}}$ & $16.6 \pm 0.8^{d}$ & $0.31 \pm 0.05^{\mathrm{c}}$ \\
\hline H788 & $37.3 \pm 3.3^{\mathrm{b}}$ & $2.8 \pm 0.2^{b c}$ & $40.9 \pm 2.0^{b}$ & $70.3 \pm 1.2^{\mathrm{c}}$ & $24.9 \pm 1.6^{\mathrm{b}}$ & $18.3 \pm 0.2^{b}$ & $0.34 \pm 0.08^{c}$ \\
\hline H834 & $40.1 \pm 1.5^{b}$ & $2.4 \pm 0.2^{\mathrm{c}}$ & $43.5 \pm 3.2^{b}$ & $65.8 \pm 1.2^{\mathrm{b}}$ & $23.5 \pm 1.4^{b c}$ & $18.0 \pm 1.2^{b}$ & $0.28 \pm 0.06^{\mathrm{e}}$ \\
\hline H835 & $37.0 \pm 2.1^{\mathrm{b}}$ & $3.2 \pm 0.2^{\mathrm{b}}$ & $39.4 \pm 2.1^{\mathrm{b}}$ & $67.6 \pm 1.5^{b}$ & $25.8 \pm 0.6^{\mathrm{b}}$ & $18.1 \pm 0.6^{\mathrm{b}}$ & $0.44 \pm 0.02^{\text {be }}$ \\
\hline H836 & $39.8 \pm 3.1^{\mathrm{b}}$ & $3.1 \pm 0.1^{\mathrm{b}}$ & $39.3 \pm 1.7^{b}$ & $63.7 \pm 2.3^{\mathrm{bd}}$ & $22.8 \pm 0.8^{\mathrm{bc}}$ & $18.2 \pm 1.3^{\mathrm{b}}$ & $0.36 \pm 0.21^{\mathrm{c}}$ \\
\hline H838 & $40.8 \pm 2.8^{b}$ & $3.1 \pm 0.5^{b c}$ & $31.3 \pm 2.7^{c}$ & $62.6 \pm 1.1^{\mathrm{d}}$ & $23.4 \pm 0.9^{b c}$ & $20.2 \pm 0.1^{\mathrm{c}}$ & $0.50 \pm 0.03^{\mathrm{d}}$ \\
\hline H841 & $42.3 \pm 2.1^{b c}$ & $3.2 \pm 0.2^{\mathrm{b}}$ & $39.2 \pm 0.7^{\mathrm{b}}$ & $71.3 \pm 2.1^{\mathrm{c}}$ & $21.6 \pm 2.0^{c}$ & $18.1 \pm 0.8^{b}$ & $0.40 \pm 0.12^{\mathrm{b}}$ \\
\hline $\mathrm{H} 843$ & $40.0 \pm 3.3^{b}$ & $2.8 \pm 0.2^{b c}$ & $40.1 \pm 0.9^{b}$ & $67.8 \pm 1.1^{\mathrm{b}}$ & $25.0 \pm 1.9^{b}$ & $17.1 \pm 0.5^{\mathrm{d}}$ & $0.42 \pm 0.05^{\mathrm{b}}$ \\
\hline H848 & $37.8 \pm 2.2^{b}$ & $2.9 \pm 0.5^{b c}$ & $38.5 \pm 3.2^{b}$ & $66.9 \pm 1.2^{b}$ & $25.4 \pm 1.1^{\mathrm{b}}$ & $18.3 \pm 0.4^{\mathrm{b}}$ & $0.39 \pm 0.03^{b}$ \\
\hline Svevo & $30.9 \pm 1.2^{\mathrm{a}}$ & $0.4 \pm 0.1^{\mathrm{a}}$ & $57.2 \pm 2.3^{\mathrm{a}}$ & $78.7 \pm 2.1^{\mathrm{a}}$ & $37.6 \pm 3.9^{a}$ & $14.5 \pm 1.4^{\mathrm{a}}$ & $0.13 \pm 0.04^{\mathrm{a}}$ \\
\hline
\end{tabular}

Averaged values calculated on two years of cultivation. Different letters indicate significant differences between means for $\mathrm{P}<0.05$. 
Impact of the SSIIa null mutations in durum wheat

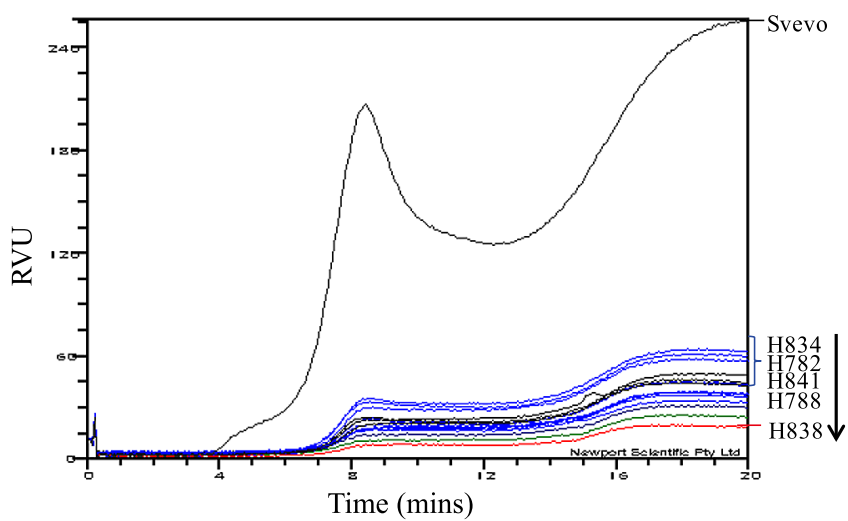

Fig. 1. Pasting profile of the set of 14 mutant families as measured by RVA. In the figure, Svevo and the mutant lines with the highest (H834, H782, H841 and H788) and the lowest (H838) viscosity curves are indicated. Viscosity (RVU).

protein content (Table 1): this increase is likely to be associated with the reduction in TS.

\section{Seed hardness}

Seed hardness was determined by SKCS methodology for a set of two SSIIa mutant lines (H795 and H806) replicated for two years; data comparison with the control line Svevo did not highlight any significant difference (data not shown).

\section{Correlation among traits}

Comparison of amylose content and thousand grain weight data highlighted a significant negative correlation $\left(r^{2}=-0.75\right)$ between the two parameters. A negative correlation has also been detected between amylose and total starch content $\left(r^{2}=-0.815\right)$.

As expected data analysis highlighted a good positive correlation between resistant starch $\left(r^{2}=0.52\right)$ and amylose content; whereas an inverse correlation of RS was found with TS $\left(r^{2}=-0.77\right)$ and TGW $\left(r^{2}=-0.68\right) . \beta$-glucans were found to be positively correlated with RS $\left(r^{2}=0.64\right)$ and at minor extent with amylose content $\left(r^{2}=0.25\right)$; a negative correlation was found with thousand grain weight $\left(r^{2}=-0.41\right)$ and total starch $\left(r^{2}=-0.77\right)$. A similar profile was found for total protein content: it was correlated positively with $\mathrm{RS}\left(r^{2}=0.39\right)$ but not with $\mathrm{AC}\left(r^{2}=0.06\right)$, and negatively with TS $\left(r^{2}=-0.62\right)$, TGW $\left(r^{2}=-0.28\right)$.

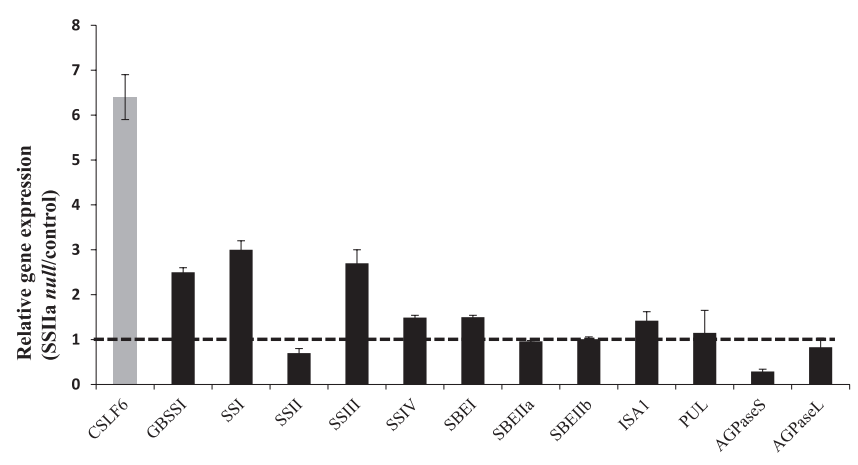

Fig. 2. Relative expression of genes coding for starch and $\beta$-glucan biosynthetic enzymes. The analysis were performed on the cultivar Svevo and the SSIIa null genotype. Dotted horizontal line at 1 level represents the value of control Svevo.

\section{Rheological evaluation of SII a null wheat semolina}

Semolinas of the two lines H795 and H806, grown in two different years, showed high values of tenacity (P), low values of extensibility (as indicated by the higher $\mathrm{P} / \mathrm{L}$ ratio), and dough strength (W) compared to the control sample (cultivar Svevo) (Table 2, Fig. 3). Concerning the farinographic curves, high amylose samples showed higher water absorption, dough development time and degree of softening compared to the cv Svevo; differently, dough stability was significantly lower.

Determination of arabinoxylans and $\beta$-glucans in semolina of SSIII null mutant lines

The same lines used for rheological tests were analyzed for arabinoxylan and $\beta$-glucan content. TOT-AX and WEAX content was highly increased in the semolina of SSIIa null lines, being 1.5-1.9 and 1.4-1.7 fold higher, respectively (Table 3). Also $\beta$-glucans were found between 2.7 and 3.4 fold higher in the two lines. Both for arabinoxylans and $\beta$-glucans it was found a major increase in the line H806. This result was confirmed in the two years of cultivation.

A strong increase of starch damage was observed for the two lines with higher amylose content compared to Svevo (Table 3).

\section{Expression profiles of starch and $\beta$-glucans related genes}

In order to gain new insights on the molecular mechanisms governing structural changes identified in SSIIa null genotypes, a set of genes coding key enzymes involved in starch and $\beta$-glucan biosynthesis were investigated at

Table 2. Rheological properties of SSIIa null durum wheat semolina

\begin{tabular}{|c|c|c|c|c|c|c|c|c|c|c|}
\hline \multicolumn{5}{|c|}{ Alveograph } & \multicolumn{6}{|c|}{ Farinograph } \\
\hline Samples & $\mathrm{P}$ & $\mathrm{L}$ & W & $\mathrm{P} / \mathrm{L}$ & $\begin{array}{c}\text { Water } \\
\text { absorption \% }\end{array}$ & $\begin{array}{c}\text { Consistency } \\
\text { (U.F.) }\end{array}$ & $\begin{array}{c}\text { Dough } \\
\text { development } \\
\text { (min.) }\end{array}$ & $\begin{array}{l}\text { Dough } \\
\text { stability } \\
\text { (min.) }\end{array}$ & $\begin{array}{l}\text { Softening } \\
\text { degree } 10 \\
\text { min. (U.F.) }\end{array}$ & $\begin{array}{c}\text { Softening } \\
\text { degree } 12 \\
\text { min. (U.F.) }\end{array}$ \\
\hline Svevo & $120 \pm 6$ & $79 \pm 5$ & $291 \pm 28$ & $2 \pm 0$ & 60 & 495 & 4 & 6 & 39 & 68 \\
\hline $\mathrm{H} 795$ & $218 \pm 6$ & $16 \pm 1$ & $159 \pm 10$ & $14 \pm 0$ & 76 & 528 & 5 & 3 & 77 & 132 \\
\hline H806 & $168 \pm 14$ & $10 \pm 1$ & $84 \pm 16$ & $17 \pm 1$ & 83 & 524 & 8 & 4 & 12 & 524 \\
\hline
\end{tabular}


A
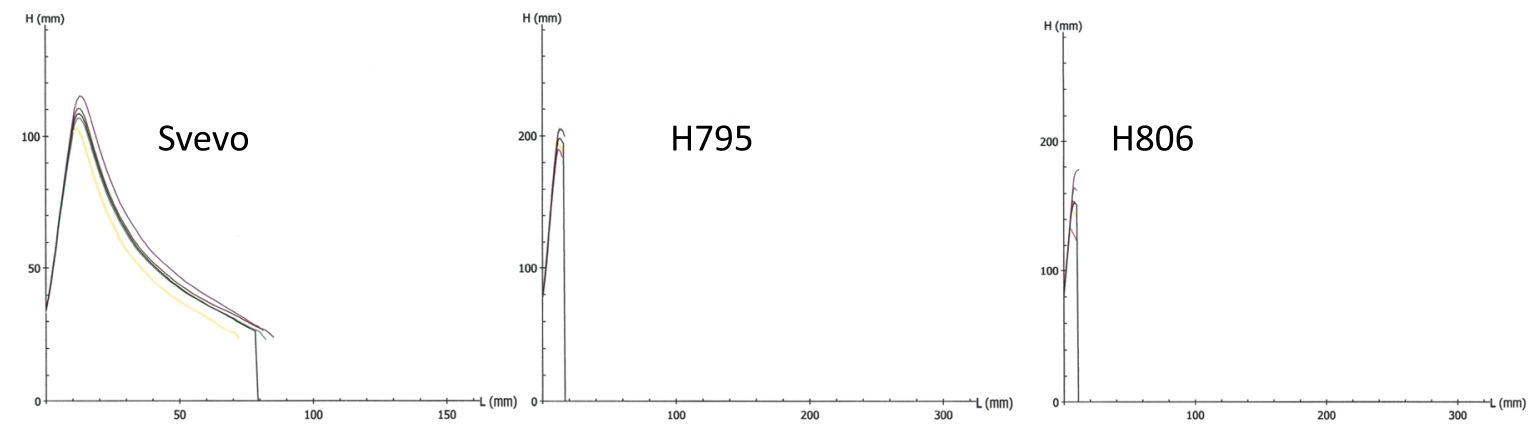

B
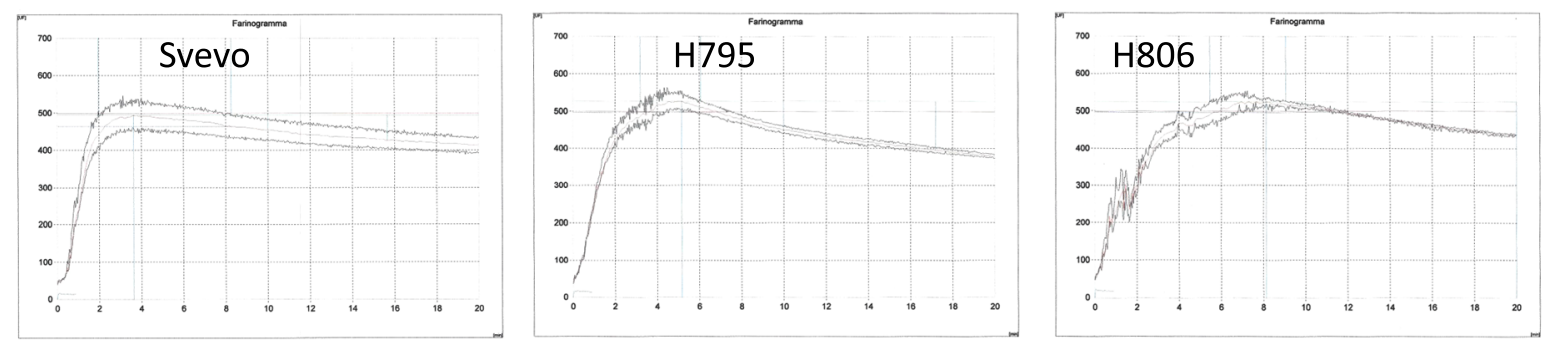

Fig. 3. Alveograph (A) and Farinograph (B) tests. The analyses were carried out on semolina of Svevo, H795 and H806 lines.

Table 3. Determination of RS, TOT-AXs, WE-AXs, $\beta$-glucans and starch damage for SSIIa null semolina

\begin{tabular}{lccccc}
\hline \hline Semolina & $\begin{array}{c}\text { Resistant } \\
\text { starch }\end{array}$ & TOT-AXs & WE-AXs & $\beta$-glucan & $\begin{array}{c}\text { Starch } \\
\text { damage }\end{array}$ \\
\hline Svevo & $1.1 \pm 0.2$ & $2.3 \pm 0.2$ & $0.59 \pm 0.04$ & $0.22 \pm 0.04$ & $4.95 \pm 0.04$ \\
H795 & $3.1 \pm 0.8$ & $3.4 \pm 0.3$ & $0.83 \pm 0.05$ & $0.60 \pm 0.04$ & $6.77 \pm 0.03$ \\
H806 & $4.1 \pm 0.5$ & $4.2 \pm 0.5$ & $1.01 \pm 0.12$ & $0.75 \pm 0.03$ & $7.19 \pm 0.03$ \\
\hline
\end{tabular}

All values are expressed in percentages ( $\mathrm{g} / 100 \mathrm{~g}$ of semolina).

expression level. Analysis was performed on RNA isolated from immature seeds (21 day post anthesis) harvested from the mutant and control lines.

SSII a genes were confirmed to be down-regulated in the SSIIa null mutant; on the contrary all the other major starch synthase genes (SSI and SSIII), involved in amylopectin synthesis, were found deeply up-regulated, roughly three fold in the double null mutant (Fig. 2). Also GBSSI (Granule Bound Starch Synthase) expression was 2.5 fold increased compared to the wild type. SSIV gene was found to be less up-regulated than other SSs in the SSIIa null genotype in agreement with the role of this enzyme, majorly involved in the synthesis of primary starch in the leaf tissue. Differently the gene expression of starch branching enzymes was poorly affected in the wheat mutant line, except for $S B E I$ gene that was found slightly up-regulated (1.5 fold). No appreciable differences were revealed for the genes coding debranching enzymes (LDA and ISA); lastly, a significant down-regulation of the AGPase small subunit gene was detected.

Cellulose Synthase-Like F6 (CSLF6) is known to be one of the major enzyme regulating $\beta$-glucans synthesis in wheat (Nemeth et al. 2010). Interestingly, our data indicated a strong increase of the expression of the CSLF6 gene in the SSIIa null line (6.4 fold) in respect to the control line.

\section{Discussion}

\section{Analysis of the set of fourteen SSIIa null lines}

In classical plant breeding the introgression of a desired trait can often be associated with pleiotropic effects some of which may have adverse effects on the overall plant performances. Crossing of the mutant plant with a high performing variety represents a valuable strategy to combine the new trait and the maintenance of good agronomic performances (Howard et al. 2014). In this work we report the characterization of major seed traits in a durum wheat genotype derived from the introgression of SSIIa null character in the elite cultivar Svevo. A large set of SSIIa null lines (144) were produced by four backcrossing cycles with the parental line Svevo, then characterized for a set of major traits such as grain yield, seed color, amylose content and viscosity properties (data not shown). A significant variability among the wheat lines was detected: from the observation of these data, a small set of families were selected and characterized either to better elucidate the relationship between SSIIa null alleles and pleiotropic effects on grain traits or to produce an improved SSIIa null durum wheat. In particular, lines with the best and worst values for grain yield were selected. The increased level of amylose amount in our mutant lines confirmed that these materials are of 
interest for their unique nutritional characteristics. Interestingly a wide variability has been reported in the response of different cereals to the absence of SSIIa enzyme: in diploid barley amylose content was $70 \%$ in the SSIIa null genotype compared to the $25 \%$ of the control line (Morell et al. 2003, Sparla et al. 2014); in bread wheat the increase in amylose was modest resulting $37 \%$ in the mutant compared to the $29 \%$ of the wild type (Yamamori et al. 2000). We previously found that in durum wheat the increase in amylose content was an intermediate value between that of barley and bread wheat; this data was recently confirmed by Hogg et al. (2013) that produced SSIIa null durum wheat.

Amylose content was found to vary from $37.0 \%$ to $46.2 \%$ among the set of fourteen SSIIa null sister lines. This variation is likely to be attributable to the different genetic backgrounds possessed by the different lines. This observation is in agreement with the hypothesis of the existence of minor factors regulating amylose content in cereals. At this purpose Wu et al. (2009) suggested that the action of major loci regulating amylose content (as waxy1, sugary-2, sugary-1 and dull) is quantitatively conditioned by minor modifier genes in amylomaize VII corn. Mohammadkhani et al. (1999) reported similar considerations for einkorn and emmer wheats and rye. As expected all the fourteen mutant lines showed a RVA profile typical of the high amylose starches in which all main parameters had strongly lowered values compared to the control (Yamamori et al. 2006).

Our data confirmed the existence of a positive correlation between amylose and resistant starch contents in the durum wheat mutant lines; RS values were comparable with those for SSIIa-null genotype of bread wheat and slightly lower in respect to the SBEIIa null durum wheat (Sestili et al. 2015, Slade et al. 2012). Hazard et al. (2012) found a minor increase of RS in the SBEIIa mutant of the durum wheat Kronos (less than 1\%) likely due to the different genetic background of the cultivar or due to the type of mutation affecting SBEIIa gene expression. In bread wheat cosuppression of both SbeIIa and SbeIIb resulted with higher values of RS (Regina et al. 2015).

Other parameters known to be affected in SSIIa null genotypes are thousand grain weight, total starch and protein content as previously reported for bread wheat and barley (Konik-Rose et al. 2007, Morell et al. 2003, Yamamori et al. 2000). Our data confirmed a much more drastic effect on total starch and seed weight in durum compared to bread wheat as already highlighted recently by Hogg et al. (2013).

The increase of protein content, observed in SSIIa null lines, is in agreement with the values measured by KonikRose et al. (2007) in the bread wheat SSIIa mutant. They supposed that the apparent increase in protein content did not represent more protein synthesis per grain, but it reflected the strong decrease in starch content.

In all fourteen SSIIa null lines $\beta$-glucan content was strongly increased compared to Svevo. $\beta$-glucans are present in the starchy endosperm cell wall representing $20 \%$ of the total. An increase in $\beta$-glucan content was previously reported both in waxy and high amylose genotypes of barley (Clarke et al. 2008, Howard et al. 2014, Xue et al. 1997). Similarly, $\beta$-glucan has been found increased in the waxy genotypes of bread wheat (Ahuja et al. 2013, Yasui et al. 1999). The increase in $\beta$-glucans originates by common substrates or enzymes between starch and $\beta$-glucan synthesis; here we provide the evidence that also in high amylose durum wheat, $\beta$-glucans content is significantly increased. The lack of SSIIa is associated with a decrease in amylopectin synthesis and total starch content, confirmed by the wrinkled/shrunken seed phenotype observed in our SSIIa null durum wheat lines; so it can be postulated that the ADP-glucose not processed by SSIIa enzyme becomes available to the other biosynthetic pathways such as that of $\beta$-glucans. A similar model was recently proposed by Islamovic et al. (2013) who, studying the genetic dissection of $\beta$-glucan and amylose content in barley, suggested an intricate co-expression network that regulates polysaccharide content in the kernel.

Zhang et al. (2012) studied carbon reallocation to other carbohydrates end products in a rice waxy mutant, reporting that only the amylopectin content increased significantly; while $\beta$-glucans, other sugars and also total starch remained almost unchanged. In contrast, Howard et al. (2014) recently reported an increase of $\beta$-glucans of $40 \%$ in a waxy barley in respect to the control; the same authors found an increase of the $\beta$-glucans/total starch ratio in a SSIIa null defective barley.

qRT-PCR experiment showed that the gene coding CSLF6 the major enzyme synthesizing $\beta$-glucans in wheat (Nemeth et al. 2010), was deeply up-regulated in the SSIIa null mutant compared to Svevo. This result correlates with the increase in $\beta$-glucan amount observed in whole flours of the mutant lines.

Various reports have investigated the relationship between amylose content and seed hardness in cereals. In maize it was proposed that hard endosperms were richer in amylose compared to soft ones (Dombrink-Kurtsman and Knutson 1997). Similarly, Clarke et al. (2008) reported an increase in seed hardness in a high amylose SSIIa null mutant of barley compared to the control line. In the material here analyzed the correlation between seed hardness and amylose content has not been observed.

\section{Semolina characterization}

The preliminary evaluation of the rheological characteristics of two elevated amylose lines highlighted a large difference in both alveographic and farinographic values and, in addition, higher water absorption compared to Svevo. This can be attributed to the increase in fiber components, such as arabinoxylans and $\beta$-glucans, and a higher starch damage (Turner et al. 2008).

Notably the semolina of the two lines H795 and H806 presents a significant increase in total arabinoxylans content. Arabinoxylans, together with $\beta$-glucans, represent the major dietary fiber in wheat grain, accounting for the $70 \%$ 
of the total cell wall polysaccharides, and are associated to a number of health benefits.

SSIIa null semolina is a raw material of particular interest for its potential health benefits as it presents an increase of different classes of dietary fibers, namely, resistant starch, arabinoxylans and $\beta$-glucans (Wood 2007). Hogg et al. (2015) recently confirmed an increase in total fiber also in the pasta made by a SSIIa null durum wheat line.

\section{Expression profiles of starch related genes}

The expression of a set of major genes directly involved in starch biosynthesis was investigated in a SSIIa null genotype. Among major classes of starch biosynthetic enzymes we found a significant increase in the expression of starch synthases; no detectable changes were found in the genes coding starch branching enzymes. The increase in the expression of SSs is likely to be due to a mechanism of compensation due to the absence of SSIIa. Interestingly GBSSI gene was also found up-regulated suggesting an attempt of the cell to metabolize glucose accumulated in the amylopectin defective mutant. Moreover the analysis showed a decrease of the transcript level of AGPase, the enzyme synthesizing ADP-glucose; this seems to be in agreement with the reduction in total starch observed in the SSIIa null sister lines. Our data are not in agreement with those of Hogg et al. (2013) who found an increase in expression of the genes coding a large subunit of AGPase and starch branching enzymes. These differences could be due to the different genetic backgrounds of the two SSIIa null durum wheats.

A further pleiotropic effect associated with the absence of the SSIIa proteins is the abolishment of the presence of the proteins Sgp-2 (SBEII) and Sgp-3 (SSI) within the starch granules (Kosar-Hashemi et al. 2007, Lafiandra et al. 2010). However our qRT-PCR experiment highlighted that these genes were not silenced: in particular no detectable changes were found in starch branching enzymes, whereas the SSI gene was even up-regulated three fold in the mutant compared to Svevo. These data support the hypothesis that the loss of the two proteins (Sgp-2 and Sgp-3) in the starch granule corresponds to their increase in the protein soluble fraction, due to the absence of the "starch granule protein complex" in the SSIIa null genotype (Luo et al. 2015).

In conclusion durum wheat collection has been enriched of new lines with interesting nutritional characteristics through the implementation of a classic breeding strategy applied to reduce undesired effects associated to SSIIa null mutant genotypes. Analysis of our data led to the identification of a set of lines showing acceptable total starch and grain yield although possessing values of amylose content and resistant starch typical of SSIIa null genotype.

Preliminary rheological data indicates that processing of these material (e.g. milling) need to be optimized using conditions specific for its characteristics and composition.

In addition, a preliminary characterization of semolina highlighted an altered composition of the non starch polysaccharides fraction that constitutes the main dietary fiber in wheat grains.

Worthy of note these materials can be defined "fiber enriched" for the increase in resistant starch, $\beta$-glucans and arabinoxylans and can provide further health benefits acting synergistically with resistant starch.

\section{Acknowledgements}

We wish to thank Dr. M. Sissons for valuable suggestions.

Research carried out with the financial support of AGER "Agroalimentare e Ricerca" (From Seed to Pasta project) and Atena "Approcci TEcnologici Nuovi per 1'Aumento della shelf- life e del contenuto di servizio nei prodotti qualificanti il modello alimentare mediterraneo".

\section{Literature Cited}

Ahuja, G., S.Jaiswal, P.Hucl and R.N.Chibbar (2013) Genomespecific granule-bound starch synthase I (GBSSI) influences starch biochemical and functional characteristics in near-isogenic wheat (Triticum aestivum L.) lines. J. Agric. Food Chem. 61: 1212912138.

Clarke, B., R.Liang, M.K. Morell, A.R. Bird, C.L.D. Jenkins and Z.Li (2008) Gene expression in a starch synthase IIa mutant of barley: changes in the level of gene transcription and grain composition. Funct. Integr. Genomics 8: 211-221.

Dombrink-Kurtzman, M.A. and C.A. Knutson (1997) A study of maize endosperm hardness in relation to amylose content and susceptibility to damage. Cereal Chem. 74: 776-780.

Finnie, S.M., A.D. Bettge and C.F. Morris (2006) Influence of cultivar and environment on water-soluble and water-insoluble arabinoxylans in soft wheat. Cereal Chem. 83: 617-623.

Hazard, B., X.Zhang, P.Colasuonno, C.Uauy, D.M.Beckles and J. Dubcovsky (2012) Induced mutations in the starch branching enzyme II (SBEII) genes increase amylose and resistant starch content in durum wheat. Crop Sci. 52: 1754-1766.

Hazard, B., X.Zhang, M.Naemeh, M.K.Hamilton, B.Rust, H.E. Raybould, J.W.Newman, R. Martin and J. Dubcovsky (2015) Mutations in durum wheat SBEII genes affect grain yield components, quality, and fermentation responses in rats. Crop Sci. 55: 28132825.

Hogg,A.C., K.Gause, P.Hofer, J.M.Martin, R.A.Graybosch, L.E. Hansen and M. Giroux (2013) Creation of a high-amylose durum wheat through mutagenesis of starch synthase II (SSIIa). J. Cereal Sci. 57: 377-383.

Hogg, A.C., J.M. Martin, F.A. Manthey and M.J. Giroux (2015) Nutritional and quality traits of pasta made from SSIIa null highamylose durum wheat. Cereal Chem. 92: 395-400.

Howard, T.P., B.Fahy, F. Leigh, P. Howell, W. Powell, A. Greenland, K. Trafford and A.M. Smith (2014) Use of advanced recombinant lines to study the impact and potential of mutations affecting starch synthesis in barley. J. Cereal Sci. 59: 196-202.

Islamovic, E., D.E. Obert, R.E. Oliver, S.A. Harrison, A. Ibrahim, J.M. Marshall, K.J.Miclaus, G.Hu and E.W.Jackson (2013) Genetic dissection of grain beta-glucan and amylose content in barley (Hordeum vulgare L.). Mol. Breed. 31: 15-25.

Kang,G.Z., W.Xu, G.Q.Liu, X.Q.Peng and T.C.Guo (2013) Comprehensive analysis of the transcription of starch synthesis genes and the transcription factor RSR1 in wheat (Triticum 
aestivum) endosperm. Genome 56: 115-122.

Konik-Rose, C., J. Thistleton, H. Chanvrier, I. Tan, P. Halley, M. Gidley, B. Kosar-Hashemi, H. Wang, O. Larroque, J. Ikea et al. (2007) Effects of starch synthase IIa gene dosage on grain, protein and starch in endosperm of wheat. Theor. Appl. Genet. 115: 1053-1065.

Kosar-Hashemi, B., Z.Li, O.Larroque, A.Regina, M.Yamamori, M.K. Morell and S.Rahman (2007) Multiple effects of the starch synthase IIa mutation in developing wheat endosperm. Funct. Plant Biol. 34: 431-438.

Lafiandra,D., F. Sestili, R. D’Ovidio, M.Janni, E. Botticella, G.Ferrazzano, M. Silvestri, R. Ranieri and E. DeAmbrogio (2010) Approaches for modification of starch composition in durum wheat. Cereal Chem. 87: 28-34.

Lafiandra,D., G. Riccardi and P.R. Shewry (2014) Improving cereal grain carbohydrates for diet and health. J. Cereal Sci. 59: 312-326.

Luo, J., R.Ahmed, B. Kosar-Hashemi, O.Larroque, V.M.Butardo, G.J.Tanner, M.L.Colgrave, N.M.Upadhyaya, I.J.Tetlow, M.J. Emes et al. (2015) The different effects of starch synthase IIa mutations or variation on endosperm amylose content of barley, wheat and rice are determined by the distribution of starch synthase I and starch branching enzyme IIb between the starch granule and amyloplast stroma. Theor. Appl. Genet. 128: 1407-1419.

Mohammadkhani,A., F.L. Stoddard and D.R. Marshall (1999) Amylose content in segregating populations of einkorn, emmer, and rye. Starch/Staerke 51: 66-73.

Morell, M.K., B. Kosar-Hashemi, M. Cmiel, M.S.Samuel, P. Chandler, S. Rahman, A. Buleon, I.L. Batey and Z. Li (2003) Barley sex6 mutants lack starch synthase IIa activity and contain a starch with novel properties. Plant J. 34: 173-185.

Nemeth,C., J.Freeman, H.D. Jones, C.Sparks, T.K.Pellny, M.D. Wilkinson, J.Dunwell, A.A.M.Andersson, P.Aman, F. Guillon et al. (2010) Down-regulation of the CSLF6 gene results in decreased $(1,3 ; 1,4)-\beta$-D-glucan in endosperm of wheat. Plant Physiol. 152: 1209-1218.

Regina,A., P.Berbezy, B.Kosar-Hashemi, S.Li, M.Cmiel, O. Larroque, A.R.Bird, S.M. Swain, C. Cavanagh, S.A. Jobling et al. (2015) A genetic strategy generating wheat with very high amylose content. Plant Biotechnol. J. 13: 1276-1286.

Sestili, F., M.Janni, A. Doherty, E. Botticella, R.D’Ovidio, S. Masci, H. Jones and D. Lafiandra (2010) Increasing the amylose content of durum wheat through silencing of the SBEIIa genes. BMC Plant Biol. 10: 144.

Sestili, F., S.Palombieri, E. Botticella, P.Mantovani, R. Bovina and D. Lafiandra (2015) TILLING mutants of durum wheat result in a high amylose phenotype and provide information on alternative splicing mechanisms. Plant Sci. 233: 127-133.

Shimbata, T., T.Nakamura, P. Vrinten, M. Saito, J. Yonemaru, Y. Seto and H. Yasuda (2005) Mutations in wheat starch synthase II genes and PCR-based selection of a SGP-1 null line. Theor. Appl. Genet. 111: 1072-1079.

Slade,A.J., C.McGuire, D.Loeffler, J.Mullenberg, W. Skinner, G. Fazio, A.Holm, K.M.Brandt, M.N.Steine, J.F. Goodstal et al. (2012) Development of high amylose wheat through TILLING. BMC Plant Biol. 12: 69.

Soh, H.N., M.J. Sissons and M.A. Turner (2006) Effect of starch granule size distribution and elevated amylose content on durum dough rheology and spaghetti cooking quality. Cereal Chem. 83: 513519.

Sparla,F., G.Falini, E. Botticella, C.Pirone, V.Talamè, R. Bovina, S. Salvi, R. Tuberosa, F. Sestili and P.Trost (2014) New starch phenotypes produced by TILLING in barley. PLoS ONE 9: e107779.

Topping, D. (2007) Cereal complex carbohydrates and their contribution to human health. J. Cereal Sci. 46: 220-229.

Turner, M.A., C.H. Soh, N.K. Ganguli and M.J.Sissons (2008) A survey of water-extractable arabinopolymers in bread and durum wheat and the effect of water-extractable arabinoxylan on durum dough rheology and spaghetti cooking quality. J. Sci. Food Agric. 88: 2551-2555.

Wood, P.J. (2007) Cereal beta-glucans in diet and health. J. Cereal Sci. 46: $230-238$.

Wu, Y.S., M. Campbell, Y. Yen, Z. Wicks III and A.M.H. Ibrahim (2009) Genetic analysis of high amylose content in maize (Zea mays L.) using a triploid endosperm model. Euphytica 166: 155-164.

Xue, Q., L. Wang, R.K. Newman, C.W. Newman and H. Graham (1997) Influence of the hulless, waxy starch and short-awn genes on the composition of barleys. J. Cereal Sci. 26: 251-257.

Yamamori, M. and T.R. Endo (1996) Variation of starch granule proteins and chromosome mapping of their coding genes in common wheat. Theor. Appl. Genet. 93: 275-281.

Yamamori, M., S. Fujita, K. Hayakawa, J. Matsuki and T. Yasui (2000) Genetic elimination of starch granule protein, SGP-1, of wheat generates an altered starch with apparent high amylose. Theor. Appl. Genet. 101: 21-29.

Yamamori, M., M.Kato, M.Yui and M.Kawasaki (2006) Resistant starch and starch pasting properties of a starch synthase IIadeficient wheat with apparent high amylose. Aust. J. Agric. Res. 57: 531-535.

Yasui, T., T. Sasaki and J. Matsuki (1999) Milling and flour pasting properties of waxy endosperm mutant lines of bread wheat (Triticum aestivum L). J. Sci. Food Agric. 79: 687-692.

Zhang, M.Z., J.H.Fang, X.Yan, J.Liu, J.S.Bao, G. Fransson, R. Andersson, C.Jansson, P. Åman and C.Sun (2012) Molecular insights into how a deficiency of amylose affects carbon allocation - carbohydrate and oil analyses and gene expression profiling in the seeds of a rice waxy mutant. BMC Plant Biol. 12: 230. 